ORIGINAL ARTICLE

\title{
Cultural diversity and work engagement in nursing: A qualitative case study analysis
}

\author{
Nazik M.A. Zakari*1, Hanadi Hamadi², George Audi ${ }^{3}$ \\ ${ }^{1}$ College of Applied Sciences, Al Maarefa University, Riyadh, Saudi Arabia \\ ${ }^{2}$ Brooks College of Health, University of North Florida, Florida, United States \\ ${ }^{3}$ School of Allied Health Sciences, Florida Agricultural and Mechanical University, Florida, United States
}

Received: June 25, 2019

DOI: $10.5430 /$ jha.v8n4p46
Accepted: July 15, 2019

URL: https://doi.org/10.5430/jha.v8n4p46

\begin{abstract}
Objective: This study highlights the importance of understanding the impact of cultural diversity on work engagement in Saudi Arabia. Nurse leaders are appointed the challenging task of maintaining and promoting state-of-the art, work engagement efforts within hospitals that differ in structure, ownership, the various generations of nurses and their cultural diversity.

Methods: The study utilized an inductive, interpretive, and explanatory multiple case study interview design of 16 nurses across 8 hospitals in Saudi Arabia.

Results: We identified three main themes: family values and background, diverse personal culture and perceived organizational microclimate.

Conclusions: This study showed that cultural differences between Saudi and expatriates nurses had an impact on work engagement. These findings are generalizable to other countries that rely heavily on immigrant nurse workers to fill the shortage. The findings from this study will create awareness of cultural interaction among nurses and its impact on nursing practice as the country transitions through a women empowerment movement while attaining Saudi's "Vision 2030".
\end{abstract}

Key Words: Cultural diversity, Nursing practice, Work engagement, Immigrant nurses, Qualitative research, Case study

\section{INTRODUCTION}

Cultural diversity spans beyond national origin, and it can be differentiated further by what Hofstede describes as mental programming within six levels of culture. Those levels range from national origin to the way employees socialize with their work organization. ${ }^{[1]}$ Hofstede and Hofstede's study found that individuals' regional, ethnic, and religious background, combined with their gender and social class, have an impact on personal behaviors. These factors may reflect how individuals engage in their work. ${ }^{[2]}$ As the minority population continues to grow, Isaacson ${ }^{[3]}$ argues, not only for cultural competency but also for cultural humility in which openness and active listening leads to an increased workplace understanding.

An overview analysis of the nursing workforce in The Kingdom of Saudi Arabia revealed the importance of five key, mutually-dependent concepts if cultural competence is to be achieved. They are cultural awareness, knowledge, skill, encounter, and desire. In addition, enhancers of cultural competence were identified and included a realization of common humanity, appreciation of different cultures, and a desire to become further educated in another's culture. ${ }^{[4]}$

${ }^{*}$ Correspondence: Nazik M.A. Zakari; Email: nzakari@mcst.edu.sa; Address: Nursing Department, College of Applied Sciences, Al Maarefa University, P.O.Box 71666, Dariyah, Riyadh 11596, Saudi Arabia. 
In the United Arab Emirates (UAE), a transactional and transformational analysis of nursing managers revealed the importance of motivation when providing nursing care in a culturally-diverse environment. ${ }^{[5]}$ The dependability of Saudi's health system on expatriate nurses' results in an increase in cultural diversity within hospitals and may affect how nurses perceive work engagement.

\section{Literature review}

Nurses working in hospitals in Saudi Arabia come from over 50 different countries and make up 75\% of the nursing workforce, creating a diverse work environment. ${ }^{[4]}$ This diversity has implications for the culture of the nursing practice in Saudi Arabia. Culture can be defined as a collection of belief systems encompassing multiple groups of individuals. For this study, the following definition of culture is considered, "The totality of socially transmitted behavioral patterns, arts, beliefs, values, customs, lifeways, and all other products of human work, and thought characteristics of a population of people that guide their world view and decision making". ${ }^{[6]}$ According to Mareno and Hart, ${ }^{[7]}$ intra-ethnic differences are a crucial aspect of cultural diversity. Multiple studies have shown that there are variation within cultural groups than across diverse cultural groups. ${ }^{[8,9]}$ Campinha-Bacote ${ }^{[10]}$ stated "no individual is a stereotype of one's culture of origin, but a unique blend of the diversity found within each culture, a unique accumulation of life experiences, and the process of acculturation to other cultures".

Multiple studies have conceptualized work engagement as the connection between work and one's values. ${ }^{[1]}$ Equivalently, Schaufeli, Martinez ${ }^{[12]}$ defined work engagement as "a positive, fulfilling, work-related state of mind that is characterized by Vigor, Dedication and Absorption". ${ }^{[12]}$ In the most recent conceptualizations, work engagement levels are determined based on exertion toward certain job attitudes. These attitudes include job involvement, job satisfaction, and organizational commitment. ${ }^{[13]}$

The personal characteristics and ability of a nurse to stay engaged are directly linked. A Swiss study from 2015 found that for nationals, work engagement and job stress increased with age, while for workers of international origin, both work engagement and job stress decreased with age. ${ }^{[14]}$ In Lewis' and Cunningham's research ${ }^{[15]}$ on nurse work engagement and burnout, they concluded that there was no difference among demographic groups, and that it was most notably transformational leadership that was directly correlated with higher engagement and lower burnout levels. Research conducted by Koch, Proynova ${ }^{[16]}$ indicates that emotional connectedness to the patient directly influences how much the nursing workforce will remain engaged in the workplace.
The nurse, in this case, creates an emotional attachment with the patient and associates the workplace as a facilitator of this attachment, ultimately creating a more engaged employee. ${ }^{[17]}$ Another study conducted at two Spanish hospitals found that social sustenance is a significant predictor of work engagement, and it significantly impacts job demands and burnout levels. ${ }^{[18]}$ Similarly, work engagement has been directly correlated to employee turnover while diversity has not had an effect on turnover among nurses. ${ }^{[19]}$

Due to the shortage of Saudi nurses and the resultant need to recruit expatriates, work engagement among Saudi Arabia's nursing workforce is highly important. A study of the Saudi Arabian nursing workforce showed higher scores in work engagement with significant differences in nurses' engagement across work settings, age, and experience. ${ }^{[20]}$ Given the increase population of expatriates, hospitals must place a higher emphasis on cultural competence. Nurses who participate in cultural-competency training prior to arriving in Saudi Arabia are less likely to experience cultural dissonance and, ultimately, disempowerment in the workplace. ${ }^{[4]}$ In addition, as perceptions vary with national backgrounds when adjusted for age and years of experience, clinical safety must be observed closely in this environment. ${ }^{[4,21]}$ Several studies showed that although engagement is important, new graduates place an added emphasis on empowerment in the workplace. ${ }^{[11,22-24]}$

Exploring cultural diversity factors impacting work engagement in Saudi Arabia is essential. In order to promote effective and efficient work engagement in a culturally diverse workforce, nurse leaders must explore the concept and its impact. Therefore, this study explores the different aspects of cultural diversity in relation to work engagement among nurses in Saudi Arabia.

\section{METHODS}

\subsection{Study design}

This study was conducted using an inductive, interpretive, and explanatory multiple case study interview design. ${ }^{[25]}$ Purposefully, this design was used to obtain findings by which we could identify aspects of cultural diversity contributing to nurses' work engagement.

\subsection{Setting and sampling}

Three big cities with the largest hospitals were selected; namely, Region A, Region B, and Region C. A list of names of all tertiary care hospitals in each city was prepared. Hospitals were numbered sequentially and randomized. A total of eight hospitals were selected that provided a broad range of services and had large patient volumes. In addition, select hospitals had different affiliations, including those affiliated 
with the Ministry of Health (MOH), the Military, and University Hospitals. Table 1 presents a number of hospitals, with affiliation, from each city.

Table 1. Number of selected hospitals from each region

\begin{tabular}{lcccc}
\hline \multirow{2}{*}{ Region } & \multicolumn{3}{c}{ Type of Affiliation } & \multirow{2}{*}{ Total } \\
\cline { 2 - 4 } & MOH & Military & University & \\
\hline Region A & 1 & 1 & 1 & 3 \\
Region B & 3 & 0 & 0 & 3 \\
Region C & 1 & 1 & 0 & 2 \\
Total & 5 & 2 & 1 & 8 \\
\hline
\end{tabular}

\subsection{Participants}

A total of 16 nurses were purposefully sampled using study criterion from eight hospitals in Saudi Arabia to participate in an in-depth, qualitative case study. ${ }^{[26]}$ Two nurses were asked to participate from each of the eight hospitals. A total of 8 Saudi nurses and 8 expatriate nurses were recruited. A quiet meeting room was reserved for the participants' inter- view.

To ensure that participants were representative of different hospitals, selection criteria was stratified and based on demographic variables such as nationality and willingness to participate that allowed for a variation in viewpoints. ${ }^{[27]}$ Nurses from all eight hospitals who expressed a willingness to participate were sampled using a stratified sampling approach. One Saudi nurse and one expatriate nurse from each hospital were invited to participate.

\subsection{Data collection}

Face-to-face, physically or via social media, guided interviews (see Table 2) using a semi-structured questionnaire were conducted in each participant's hospital. The semistructured interview questions were constructed based on the Utrecht Work Engagement Scale (UWES) English short form. The tool is comprised of 17 items that measure the three categories of work engagement: absorption (6 items); dedication (5 items); and vigor (6 items). ${ }^{[28]}$

Table 2. In-depth interview guide

\begin{tabular}{|c|c|c|}
\hline $\begin{array}{l}\text { Work Engagement } \\
\text { Dimension }\end{array}$ & Definition & Main Questions \\
\hline $\begin{array}{l}\text { Overall Work } \\
\text { engagement }\end{array}$ & & $\begin{array}{l}\text { 1. In your own words, can you tell me what work } \\
\text { engagement means to you? } \\
\text { 2. How does your culture affect your work } \\
\text { engagement? Please provide some examples? } \\
\text { 3. In your opinion, what are some factors that affect a } \\
\text { nurse's level of engagement at work? Ex. Type of } \\
\text { tasks, time of day, age, experience and supervisor. }\end{array}$ \\
\hline Absorption & $\begin{array}{l}\text { "Absorption, is characterized by being fully } \\
\text { concentrated and happily engrossed in one's } \\
\text { work, whereby time passes quickly and one has } \\
\text { difficulties with detaching oneself from work." } \\
\text { [26-27] }\end{array}$ & $\begin{array}{l}\text { 1. When I am working, I forget everything else around } \\
\text { me, when do you feel like that? Explain when and } \\
\text { why? }\end{array}$ \\
\hline Vigor & $\begin{array}{l}\text { "Vigor is characterized by high levels of energy } \\
\text { and mental resilience while working, the } \\
\text { willingness to invest effort in one's work, and } \\
\text { persistence even in the face of difficulties." [26-27] }\end{array}$ & $\begin{array}{l}\text { 1. In your opinion, why do some nurses be able to } \\
\text { continue to work for very long periods at a time and } \\
\text { some not? } \\
\text { 2. Under what circumstances does that happen to you } \\
\text { and why? }\end{array}$ \\
\hline Dedication & $\begin{array}{l}\text { "Dedication refers to being strongly involved in } \\
\text { one's work and experiencing a sense of } \\
\text { significance, enthusiasm, inspiration, pride, and } \\
\text { challenge." [26-27] }\end{array}$ & $\begin{array}{l}\text { 1. Do you feel that your work has a purpose?/Do you } \\
\text { consider your work to be significant? How } \\
\text { significant? Is it important to you? Why? } \\
\text { 2. Why do some nurses feel so proud of the work and } \\
\text { others don't? } \\
\text { 3. What about you, do you feel proud of your work, } \\
\text { why or why not? }\end{array}$ \\
\hline
\end{tabular}

Before the interview, the researcher met with participants individually, either in the nursing interview room or via visual media such as Skype. The interviews were scheduled at a time convenient to the participants. The primary investigator conducted the interview for the rich experience used with qualitative methods. To ensure rigor, the semi-structured 
interview questions were piloted using a purposeful sample of two Saudi and two non-Saudi nurses. Based on this pilot interview analysis, additional probing questions were developed, and the in-depth interview guide was revised (see Table 2). The central quantitative research question was, "Is there any difference between Saudi and expatriate nurses in work engagement?" Each participant was interviewed for 45 to 60 minutes in English. All interviews were recorded using an audio recorder. Afterward, each participant received a gift card to a local bookstore.

\subsection{Ethical considerations}

Ethical clearance to conduct the study was received through the University's institutional review board and hospital's research ethics committees. Each participant signed a consent form prior to participating in the study. Throughout the study, the protection of human rights was upheld, and strict adherence to ethical principles was maintained. In addition, the methodologies used was non-invasive and presented minimal or no risks to participants. Total confidentiality was established and the anonymity of participants in the study was assured through the use of pseudo names.

\subsection{Data analysis}

Verbatim transcription was completed on all interviews. The transcriptions were sent to the participants for verification and adequate cross-referencing. ${ }^{[30]}$

ATLAS.it7 software was used to organize, manage, analyze, and perform margin-area coding. ${ }^{[31]}$ The coding process was performed within each case and across the cases on three levels: descriptive, interpretative, and pattern coding. ${ }^{[30,32]}$ The transcripts were read independently and searched for similar words, patterns, and themes. Thematic analysis was conducted and cross-referenced between cases. The investigator systematically synthesized classified categories and facilitated the emergence of themes and patterns. This approach permitted the investigator to recognize important patterns and themes. Interpretations emerged from examining the entire interview in relation to its parts. Then, themes were cross-referenced against the original transcripts.

\subsubsection{Rigor}

The dependability of data sources and analyses was established and ensured using the four criteria of Lincoln and Guba (1985): credibility, transferability, dependability, and confirmability. Member-checking and tracking peer debriefing was used to maintain credibility. ${ }^{[33]}$ Detailed descriptions were extracted from the interviews and subjected to reflection to secure transferability and confirm procedures. Dependability and conformability were guaranteed using the inter-coder approach. ${ }^{[33]}$ Triangulation was achieved using multiple data Published by Sciedu Press sources from a survey conducted related to work engagement. ${ }^{[20]}$ Additionally, primary investigator notes provided additional richness to the study findings. ${ }^{[34]}$

\section{RESULTS}

A total of fifty-six codes were extracted to create six categories from the series of case studies designed to elicit cultural diversity in relation to work engagement among nurses in Saudi Arabia. Three prominent themes emerged: family values and background; diverse personal culture; and perceived organizational microclimate. Each of these themes will be discussed. Figure 1 illustrates the thematic process.

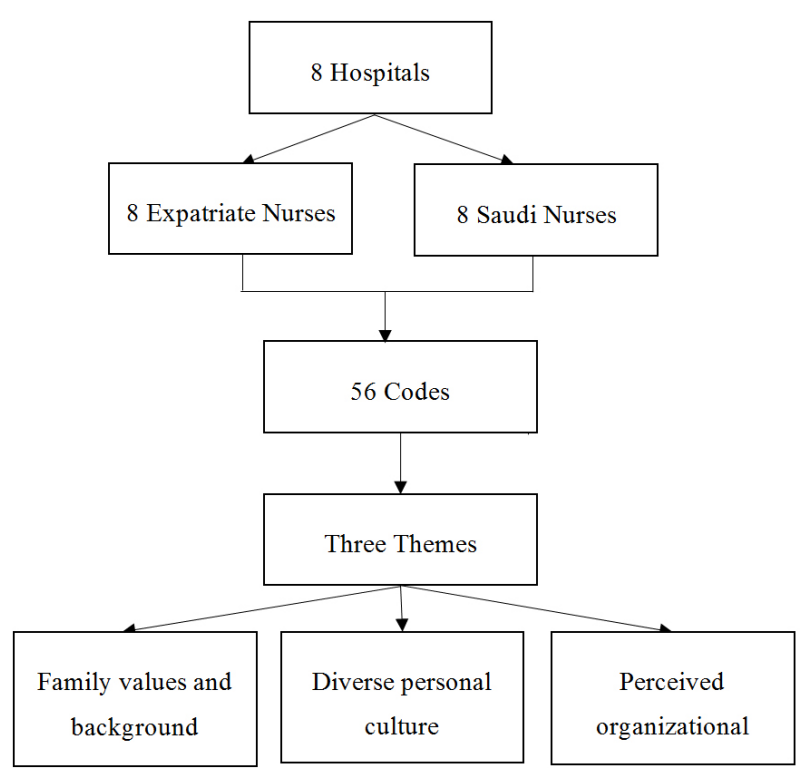

Figure 1. Thematic process

\subsection{Theme 1: Family values and background}

The concept of family is a powerful and important social institution for participants. In particular, the cultural view of the nursing profession affected work performance among Saudi families. One Saudi nurse commented,

"My work is important, as is my family and how they feel about my job. My family sends a clear, constant message that nursing is not a prestigious profession compared to others (two of my sisters are physicians). This translates into dissatisfaction with my job, which results in my being absent more often."

The second influence is related to the level of decisionmaking authority exercised by men, which governs a woman's ability to work in some family dynamics. The nurse added,

"Family commitment is the most important priority. Since I got married, my work commitment has diminished, which 
has affected my work engagement because it is no longer a priority in the eyes of my husband. Dropping me off at work falls to my husband; often, he refuses to do so, which affects my engagement . . . I do not feel happy. Also, the lack of reliable transportation contributes to my absence from work. My husband does not consider this a problem because he does not consider my job is essential."

The third influence is related to family values. A Saudi staff nurse described feelings of powerlessness and hopelessness that negatively affect work engagement:

"Due to the hospital work environment, my family is not supportive. They do not consent to my working, in particular, my interacting with the opposite gender in the field through interdisciplinary teams. I constantly feel helpless because of my family's lack of understanding. I am sure that many nurses suffer from the same feeling and similar family circumstances because of their culture. I feel indolent and discouraged toward my work."

\subsection{Theme 2: Diverse personal culture}

The state of fulfillment experienced by nurses at work can be viewed as positive or negative depending upon their personal culture. Diverse personal cultures were observed during interviews. Determining how nurses from different nationalities, regions, and generations are perceived highlighted the factors that promote work engagement. A Saudi nurse director explained,

"The belief in having the mental and physical resources to engage myself at work is meaningful, and it is influenced by the nature of the job. Some nurses have faith in their task and role, but some do not. My engagement is mainly influenced by the social environment and interpersonal relationships, combined with social norms. My personal culture is the resources I can bring to my work, such as physical energy, respectful group dynamics, and proper management style. This is my engagement."

An expatriate unit manager described some personal culture:

"While nursing labor laws remain vague, Saudi nurses place a high value on flexible working arrangements to fulfill their social duties; lack of work engagement and absenteeism are high. This impacts a patient's needs and the quality of nursing care. It has a considerable impact on those newest to the workforce. It also puts pressure on those who remain in the field, resulting in decreased morale and, potentially, further disengagement."

Theme 3: Perceived organizational microclimate: Regarding the combination of nurses' perceptions of, and feelings about, their work environment and how this reflects on their work engagement, two staff nurses described their struggle. The first expatriate said,

"Doing my work does not mean that I have positive work engagement. If we have a system to share meaning and understanding, we can positively distinguish ourselves from other hospitals. I think a lot of nurses think the same way, but if I bring it up, they don't want to talk about it. However, we should talk about it to improve our patient nursing care and outcomes. This is my point of view, and I would like to send my thoughts to the hospital or higher authority in $\mathrm{MOH} . "$

The second expatriate, a staff nurse, expressed,

"I feel that I do not fit. My expectations and actual work conditions are complete opposites. My work has no meaning to me. I was treated unfairly and not rewarded, and I did not have good relationships in the workplace. Some policies or regulations resolve work conditions on paper, but I don't always get that reinforcement in practice. In addition, I want more balance between my life and work."

However, an expatriate unit manager had a different view of the workplace microclimate:

"I feel fortunate to work where I do because I have no social restraints or difficulties. The director understands our needs and reduces work demand. In addition, the workplace stimulates personal and professional growth. I am rarely ever put on the defensive. . . In theory, if we had clear nursing labor laws, our rights would be protected . . e essentially, she supports our autonomy. This encourages optimism and emotional stability."

\section{Discussion}

The participants stressed their sense of pride, and expatriate nurses associated their pride with their own devotion. Unsurprisingly, Saudi nurses did not perceive their work to be meaningful, inspiring, or challenging. This viewpoint emerged during the in-depth interviews, in which one Saudi nurse remarked on the "fatal message that the nursing profession is not a prestigious career". This may explain why Saudi nurses have lower work engagement scores across all elements.

One key purpose of the current investigation was to better understand how cultural diversity fosters work engagement. Interestingly, our findings disclose that Saudi nurses were associated with a low voice, less energy, zest, and stamina related to work. Hospitals in Saudi Arabia are complex and rely heavily on a nursing workforce composed primarily of expatriates. ${ }^{[35]}$ A strong view of vigor is necessary. Endorsing high energy, resilience, and a willingness to put forth 
extra effort is a favorable element and beneficial aspect of the health organization. This study detected how to promote willingness. In our study one participant showed the need for "creating a work environment to suit Saudi nurses". This confirms that emotional connectedness, social sustenance, and established resources, both job-related and personal, are directly influenced by the extent to which nurses remain engaged in the workplace. ${ }^{[16,18,36]}$ This finding adds to a growing body of research concerned with the future of the nursing workforce, patient safety, and quality of nursing care in Saudi Arabia. ${ }^{[4,20]}$ Therefore, positive feelings and involvement at home and work demonstrate higher engagement. Likewise, job characteristics that might be considered resources, motivators or energizers, such as social support, are clearly linked to work engagement. ${ }^{[37]}$

Furthermore, this study attempts to interpret cultural diversity issues related to work engagement. The qualitative interpretation showed that many factors affect work engagement, including, but not limited to, family values, powerlessness and hopelessness, men ideology and privilege, nursing professional status, a combination of social norms with work environment and interpersonal relationships, declining morale, organizational microclimate perception, and emotional stability and work condition expectations. The country of Saudi Arabia is undergoing a major transformation, changing cultural norms to empower women and keep the nursing work environment safe as this transformation is led by Saudi Arabia's "Vision 2030." The Saudi Commission for Health Specialties (SCFHS) has been granted the authority to provide competent and safe health care practitioners through registration, credentialing, and continued professional development. ${ }^{[38]}$ This process will play an essential role in the transformation that will encourage and promote Saudi nurse engagement.

\section{Limitations}

This study has limitations. First, for most nurses in Saudi Arabia, English is a second language, which can limit the ability of the participants to comprehend the content of this semi-structured questionnaire. Second, the semi-structured tool did not expand on the concept of cultural diversity within an organization and was limited to the diversity of the workforce based on nationality.

\section{Conclusions}

Conceptually, work engagement is genuinely seeking or providing significant work that empowers individuals to live with unique values. ${ }^{[39]}$ Numerous factors have been identified and can be considered resources for leaders in the clinical nursing setting to promote work engagement within a diverse work environment. Findings of this study showed that cultural differences between Saudi and expatriate nurses may have an impact on work engagement dimensions. These findings may be generalizable to other countries that rely heavily on immigrant nurses to fill the nursing shortage; however, additional research in this area is needed.

In light of the national transformation program "Vision 2030", promoting and protecting health in Saudi Arabia and requiring the development of policies and guidelines for health care practitioners based on the highest standards and best practices, will lead to better work engagement. Improving nurses' work engagement can be achieved by improving their skills, competencies, and their ability to minimize cultural disaffection by considering all factors should be explored.

\section{SUMMARY STATEMENT}

\section{What is already known about this topic?}

- Nurses working in a hospital in Saudi Arabia come from over 50 different countries and make up 75\% of nursing workforce, which creates a unique diverse work environment that influenced the culture of nursing practice.

- Work engagement is a variable among nurses, influenced by many factors that are derived from professional characteristics and cultural influences.

- The shortage of nurses in Saudi Arabia emphasizes the need to recruit professional expertise.

\section{What will this paper add?}

- Family values and background, diverse personal culture and perceived organizational microclimate perceived factors impact nurses work engagement.

- Professional and personal characteristics such as educational level, marital status and position were found to impact work engagement levels.

\section{The implications of this paper}

- Saudi Arabia is undergoing major transformation that is changing cultural norms. Mutually, this transformation is led by Saudi Arabia's "Vision 2030", which will guide recruitment processes within cultural context and readiness of work engagement.

- Increasing level of awareness of nursing leader regarding the dynamic of cultural interaction among nurses and its impact on nursing practice.

- The women empowerment movement in the country will demonstrate the value of the nursing profession in the workplace while attaining Saudi's "Vision 2030". 


\section{ACKNOWLEDGements}

The authors extend their appreciation to all study participants and respective universities.

\section{CONFlicts OF InTEREST Disclosure}

The authors declare they have no conflicts of interest.

\section{REFERENCES}

[1] Hofstede G, Hofstede GJ. Cultures and Organizations: Software of the mind. Prague, Linde; 2006.

[2] Forgon T. Increasing organizational culture and ethics in healthcare organizations. Zeszyty Naukowe Organizacja i Zarządzanie/Politechnika Śląska. 2018.

[3] Isaacson M. Clarifying Concepts: Cultural Humility or Competency. Journal of Professional Nursing. 2014; 30(3): 251-8. https : //doi.org/10.1016/j.profnurs. 2013.09.011

[4] Almutairi AF, McCarthy A, Gardner GE. Understanding cultural competence in a multicultural nursing workforce: Registered nurses' experience in Saudi Arabia. Journal of Transcultural Nursing. 2015; 26(1): 16-23. PMid: 24626280. https://doi.org/10.1177/10 43659614523992

[5] El Amouri S, O'Neill S. Leadership style and culturally competent care: Nurse leaders' views of their practice in the multicultural care settings of the United Arab Emirates. Contemporary Nurse. 2014 48(2): 135-49. PMid: 25549708. https : //doi .org/10.1080/10 376178.2014 .11081936

[6] Purnell LD, Fenkl EA. The Purnell Model for Cultural Competence. Handbook for Culturally Competent Care: Springer; 2019. 7-18 p. https://doi.org/10.1007/978-3-030-21946-8_2

[7] Mareno N, Hart PL. Cultural Competency Among Nurses with Undergraduate and Graduate Degrees: Implications for Nursing Education. Nursing Education Perspectives (National League for Nursing). 2014; 35(2): 83-8. https://doi.org/10.5480/12-834.1

[8] Shen Z. Cultural competence models and cultural competence assessment instruments in nursing: a literature review. Journal of Transcultural Nursing. 2015; 26(3): 308-21. PMid: 24817206 https://doi.org/10.1177/1043659614524790

[9] Henderson S, Horne M, Hills R, et al. Cultural competence in healthcare in the community: a concept analysis. Health \& Social Care in the Community. 2018; 26(4): 590-603. PMid: 29516554. https://doi.org/10.1111/hsc. 12556

[10] Campinha-Bacote J. The Process of Cultural Competence in the Delivery of Healthcare Services: A Culturally Competent Model of Care. 4th ed. Associates TCARE, editor. Cincinnati, OH: Transcultural C.A.R.E. Associates; 2003

[11] Ziedelis A. Perceived Calling and Work Engagement Among Nurses. Western Journal of Nursing Research. 2019; 41(6): 816-33. PMid: 29591587. https://doi.org/10.1177/0193945918767631

[12] Schaufeli WB, Martinez IM, Pinto AM, et al. Burnout and Engagement in University Students: A Cross-National Study. Journal of Cross-Cultural Psychology. 2002; 33(5): 464-81. https: //doi.org/10.1177/0022022102033005003

[13] Rich KL, Nugent KE. A United States perspective on the challenges in nursing education. Nurse Educ Today. 2010; 30(3): 228-32. PMid: 19932531. https://doi.org/10.1016/j.nedt.2009.10.015

[14] Pocnet C, Antonietti JP, Massoudi K, et al. Influence of individual characteristics on work engagement and job stress in a sample of national and migrant workers in Switzerland. Personality \& Individual Differences. 2015; 60: S60-S60. https://doi.org/10.1016/j. paid.2013.07.258
[15] Smith-Lewis H, Cunningham CJL. Linking Nurse Leadership and Work Characteristics to Nurse Burnout and Engagement. Nursing Research. 2016; 65(1): 13-23. https://10.1097/NNR. 00000000 00000130

[16] Koch SH, Proynova R, Paech B, et al. The perfectly motivated nurse and the others: workplace and personal characteristics impact preference of nursing tasks. Journal of Nursing Management. 2014; 22: 1054-64. PMid: 24033771. https://doi.org/10.1111/jonm.1 2083

[17] Van Bogaert P, Adriaenssens J, Dilles T, et al. Impact of role-, joband organizational characteristics on Nursing Unit Managers' work related stress and well-being. Journal of Advanced Nursing. 2014; 70(11): 2622-33. PMid: 24842679. https ://doi.org/10.1111/ jan. 12449

[18] García-Sierra R, Fernández-Castro J, Martínez-Zaragoza F. Relationship between job demand and burnout in nurses: Does it depend on work engagement? Journal of Nursing Management. 2016; 24(6): 780-8. PMid: 27111251. https://doi.org/10.1111/jonm.123 82

[19] Collini SA, Guidroz AM, Perez LM. Turnover in health care: the mediating effects of employee engagement. Journal of Nursing Management. 2015; 23(2): 169-78. PMid: 24118346. https ://doi .or g/10.1111/jonm.12109

[20] Aboshaiqah AE, Hamadi HY, Salem OA, et al. The work engagement of nurses in multiple hospital sectors in Saudi Arabia: a comparative study. Journal of Nursing Management. 2016; 24(4): 540-8. PMid: 26749246. https://doi.org/10.1111/jonm. 12356

[21] Ammouri A, Tailakh A, Muliira J, et al. Patient safety culture among nurses. International nursing review. 2015; 62(1): 102-10. PMid: 25495946. https://doi.org/10.1111/inr.12159

[22] Boamah S, Laschinger $H$. Engaging new nurses: the role of psychological capital and workplace empowerment. Journal of Research in Nursing. 2015; 20(4): 265-77. https ://doi .org/10.1177/1744 987114527302

[23] Laschinger HKS, Cummings G, Leiter M, et al. Starting out: a timelagged study of new graduate nurses' transition to practice. International Journal of Nursing Studies. 2016; 57: 82-95. PMid: 27045567. https://doi.org/10.1016/j.ijnurstu.2016.01.005

[24] Enwereuzor IK, Ugwu LI, Eze OA. How Transformational Leadership Influences Work Engagement Among Nurses: Does Person-Job Fit Matter? Western Journal of Nursing Research. 2018; 40(3): 34666. PMid: 27920346. https://doi.org/10.1177/0193945916 682449

[25] Zinn JO, McDonald D. Research design and methods. Risk in The New York Times (1987-2014): Springer; 2018. 67-79 p. https: //doi.org/10.1007/978-3-319-64158-4_3

[26] Creswell JW, Clark VLP. Designing and Conducting Mixed Methods Research. 3rd ed. Singapore: Sage Publications, Inc.; 2018

[27] Mason J. Qualitative researching: Sage; 2017.

[28] Schaufeli WB, Bakker AB. Utrecht work engagement scale: Preliminary manual. Occupational Health Psychology Unit, Utrecht University, Utrecht. 2003; 26. https ://doi .org/10.1037/t071 64-000 
[29] Schaufeli WB, Shimazu A, Hakanen J, et al. An Ultra-Short Measure for Work Engagement: The UWES-3 validation across five countries. 2017. https://doi .org/10.1027/1015-5759/a000430

[30] Rossman GB, Rallis SF. Learning in the field: An Introduction to Qualitative Research. 3rd ed. Thousand Oaks, CA: SAGE Publications; 2011.

[31] Friese S. Using ATLAS.ti for Analyzing the Financial Crisis Data. Forum: Qualitative Social Research. 2011; 12(1): 1-24.

[32] Yin RK. Case Study Research: Design and Methods. Thousand Oaks, CA: Sage; 2003.

[33] Lincoln YS, Guba EG. Naturalistic inquiry: Sage; 1985. https: //doi.org/10.1016/0147-1767 (85)90062-8

[34] Hays DG, Singh AA. Qualitative Inquiry in Clinical and Educational Settings. New York Guilford Press; 2012.

[35] Zakari N, Al Khamis N, Hamadi H. Conflict and professionalism: perceptions among nurses in Saudi Arabia. International nursing re- view. 2010; 57(3): 297-304. PMid: 20796058. https ://doi.org/ $10.1111 / \mathrm{j} .1466-7657.2009 .00764 . \mathrm{x}$

[36] Bakker AB, Demerouti E, Isabel Sanz-Vergel A. Burnout and Work Engagement: The JD-R Approach. 2014. https ://doi .org/10.1 146/annurev-orgpsych-031413-091235

[37] Montgomery AJ, Peeters MCW, Schaufeli WB, Den Quden M. Workhome interference among newspaper managers: its relationship with burnout and engagement. Anxiety, Stress \& Coping. 2003; 16(2): 195. https://doi.org/10.1080/1061580021000030535

[38] Abdo AA, Bodrick MME. The commission in 2020: A transformation journey worth taking! Journal of Health Specialties. 2017; 5(3): 127-8. https://doi.org/10.4103/jhs.JHS_56_17

[39] Vinje HF, Mittelmark MB. Community Nurses Who Thrive: The Critical Role of Job Engagement in the Face of Adversity. Journal For Nurses in Staff Development (JNSD). 2008; 24(5): 195-202. PMid: 18838896. https://doi.org/10.1097/01.NND.00003 20695.16511.08 